\title{
Effect of Chewing Paneer and Cheese on Salivary Acidogenicity: A Comparative Study
}

\author{
Tabassum Tayab, Kavitha Rai, Vasantha Kumari, Eapen Thomas
}

\section{ABSTRACT}

Aim: The aim was to evaluate the salivary $\mathrm{pH}$ reversal phenomenon by chewing paneer and processed cheese after a chocolate challenge.

Materials and methods: Thirty caries-free children were randomly selected and divided into 2 groups: Control group was given processed cheese (Amul) and the experimental group was given paneer (Amul) after a chocolate challenge. After determining the resting salivary $\mathrm{pH}$ using $\mathrm{GC}$ pH strips, the subjects were asked to eat the test foods and salivary $\mathrm{pH}$ was measured at time intervals of $5,10,15,30$ and 60 minutes to record the time taken for the salivary $\mathrm{pH}$ to return to baseline values after an acidogenic challenge.

Results: The data was analyzed and intergroup comparison was done using paired student's t-test. The test meals increased salivary $\mathrm{pH}$ after chocolate challenge significantly from baseline values and neutralized the fall in $\mathrm{pH}$ after a chocolate challenge. The protective effect was evident after 5 minutes of consuming chocolate and was highest up to 30 minutes after which the salivary $\mathrm{pH}$ gradually fell but had not returned to baseline values even at 60 minutes.

Conclusion: The findings suggest that chewing of paneer like cheese abolishes the fall in salivary $\mathrm{pH}$ caused by sugar consumption and maybe recommended as a protective food in pediatric diet counseling.

Keywords: Cheese, Paneer, Salivary pH, Diet counseling, Protective foods.

How to cite this article: Tayab T, Rai K, Kumari V, Thomas E. Effect of Chewing Paneer and Cheese on Salivary Acidogenicity: A Comparative Study. Int J Clin Pediatr Dent 2012;5(1):20-24.

Source of support: Nil

Conflict of interest: None declared

\section{INTRODUCTION}

There is sufficient evidence regarding the effect of saliva in controlling plaque $\mathrm{pH}$, and that stimulation of saliva by foods is an important factor in determining their acidogenic potential. This is especially important when saliva is stimulated after plaque $\mathrm{pH}$ is lowered by an acidogenic challenge. ${ }^{1,2}$ Chewing of certain foods, such as cheese promotes a rapid recovery of plaque $\mathrm{pH}$ following an acidogenic challenge thereby exerting a caries protective effect. (Geddes et al, 1977; Jensen et al, 1984; Rugg-Gunn et al, 1975). ${ }^{3-5}$

Dental caries is an infectious and nutrition-related disease. Eating patterns and especially consumption of sugary foods between meals can result in tooth decay. ${ }^{6}$ Diet counseling forms an important part of preventive dentistry and as dentists see more caries-prone patients they are increasingly called upon to identify and give advice on foods that inhibit the carious process, rather than, systemic nutritional counseling for developing a caries-resistant tooth. Prevention of excess sucrose consumption appears to be a reasonable component of a caries prevention program. ${ }^{7}$ Yet, there is presently no evidence demonstrating the effectiveness of this restrictive approach of dietary counseling on caries reduction in children due to poor compliance.

Although dairy products are proven to be caries protective foods, individuals make food choices in the context of their culture, and owing to the lack of availability and high cost of cheese in the Indian subcontinent, paneer the traditional Indian cheese was chosen as the test food in this study. Paneer is an unsweetened, unripened form of cheese made by the addition of lime juice to milk which retains the noncariogenic components of milk. It contains a higher protein and phosphate content when compared to cheese but it is not known how this affects its cariogenic potential. $^{8}$

In the present study assessing the acidogenic potential of paneer, was designed using a standard acidogenic challenge to allow comparison of two types of cheese. The aim was to evaluate the salivary $\mathrm{pH}$ reversal phenomenon by chewing paneer and processed cheese after a chocolate challenge. Past research used plaque telemetry ${ }^{5}$ to measure acidity but we used salivary $\mathrm{pH}$ to develop a clinically usable patient-specific procedure for dietary counseling in children.

\section{MATERIALS AND METHODS}

A total of 36 volunteers were randomly selected from the outpatients who reported to the Department of Pedodontics and Preventive Dentistry, Sri Ramachandra Dental College, Chennai. The inclusion criteria were healthy children ranging in age from 5 to 12 years and caries free and from whom consent was obtained. A total of 17 males and 19 females were included in the study. Subjects with caries, history to food allergies especially to dairy products and were unwilling to participate were excluded. Approval for the research was obtained from the Ethical Committee of Sri Ramachandra Dental College and University, Chennai and informed consent from each participant prior to the start of the study was obtained. 
The subjects were divided into two groups: Control group was given processed cheese (Amul) and the experimental group was given paneer (Amul) after a chocolate challenge (Cadbury Dairy Milk Chocolate Bar- 12.5 gm). Since the commercially available chocolate weighs $12.5 \mathrm{gm}$ the same quantity of test foods were weighed and used.

Oral prophylaxis was done for all the subjects in the study and control group 24 hours prior to study and were instructed to refrain from eating or drinking at least 2.5 hours prior to the test. They were instructed to rinse their mouth with distilled water.

\section{SALIVARY PH MEASUREMENTS}

Unstimulated saliva was collected by Navazesh (1993) spitting method ${ }^{9}$ by pooling saliva for 60 seconds and then spitting in a plastic disposable container. Salivary $\mathrm{pH}$ was measured using GC pH strips. A single sheet of test paper was removed from the booklet. The $\mathrm{pH}$ strip was dipped into the saliva till it is fully wet and removed immediately. After 30 seconds the acids produced react to these $\mathrm{pH}$ indicators, thus leading to a colorimetric change which was compared with the color code chart and the $\mathrm{pH}$ value was noted whilst the paper was moist. ${ }^{10}$

After determining the resting salivary $\mathrm{pH}$ the subjects were asked to eat chocolate and salivary $\mathrm{pH}$ was measured at time intervals of 5, 10, 15, 30 and 60 minutes to record the time taken for the salivary $\mathrm{pH}$ to return to baseline values after an acidogenic challenge. ${ }^{11,12}$ The same subjects were then asked to rinse thoroughly with tap water and the baseline $\mathrm{pH}$ was measured as described above. After this the subjects were asked to eat chocolate again and salivary $\mathrm{pH}$ was measured at 5 minutes. The subjects were then instructed to eat cheese and paneer 5 minutes after the chocolate challenge and salivary $\mathrm{pH}$ measured at $0,5,10$, 15, 30 and 60 minutes. All readings were taken 30 seconds after insertion of test strip in saliva (Fig. 1).

The maximum $\mathrm{pH}$ attained with each test food after chocolate challenge and the difference between resting salivary $\mathrm{pH}$ and maximum salivary $\mathrm{pH}$ was established. The mean salivary $\mathrm{pH}$ values were tabulated and significance was calculated using student's paired t-test. The value was considered significant when p-value was less than 0.05 .

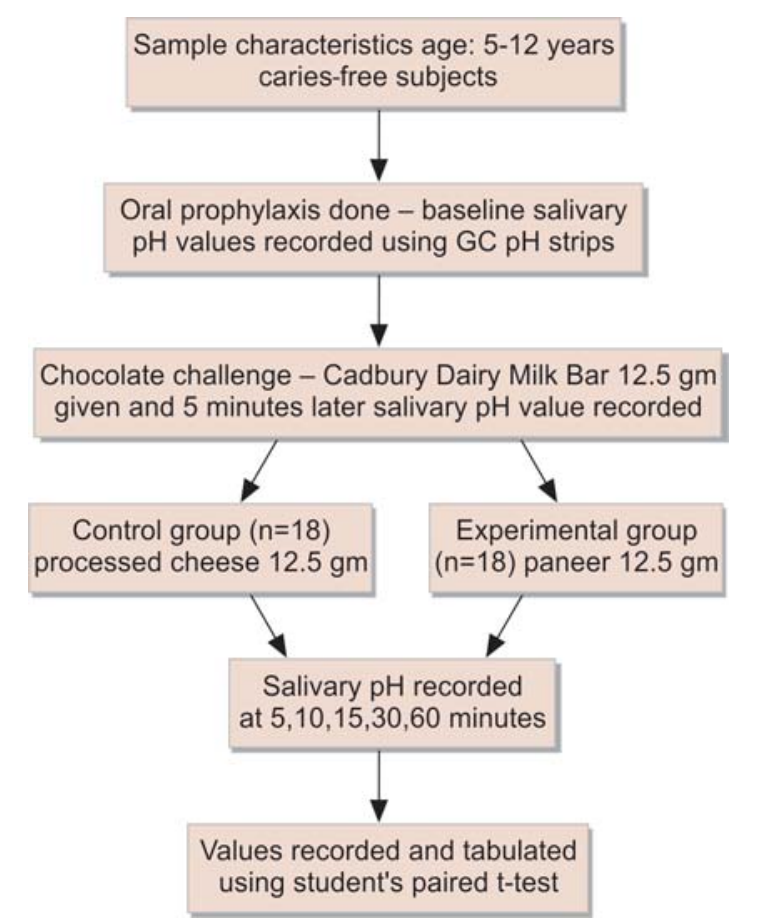

Fig. 1: Experimental method for testing the effect of chewing paneer and processed cheese on salivary $\mathrm{pH}$ after chocolate challenge

\section{RESULTS}

After eating chocolate salivary $\mathrm{pH}$ in both the groups showed minimum $\mathrm{pH}$ drop at 5 minutes and this remained significantly lower $(\mathrm{p}<0.05)$ than the baseline in all of the test periods. However, the drop in salivary $\mathrm{pH}$ after eating chocolate when compared to the salivary $\mathrm{pH}$ after eating paneer was statistically significant $(\mathrm{p}<0.001)$. Paneer did not make a great change in salivary $\mathrm{pH}$ with time. In the first minute after eating paneer salivary $\mathrm{pH}$ showed a significant increase $(p<0.001)$ from baseline. Thereafter the $\mathrm{pH}$ showed a small decrease after 5 minutes but stayed significantly higher than baseline value even at 60 minutes (Table 1).

There was a significant rise in salivary $\mathrm{pH}$ from baseline to after eating cheese $(p<0.05)$ for all the test periods. There was a drop in salivary $\mathrm{pH}$ after eating chocolate when compared to the salivary $\mathrm{pH}$ after eating cheese and was found to be statistically significant $(\mathrm{p}<0.01)$ (Table 2 ).

The mean salivary $\mathrm{pH}$ response to chocolate shows an initial sharp rise followed by a fall in $\mathrm{pH}$ reaching a minimum

\begin{tabular}{lccccc}
\multicolumn{7}{c}{ Table 1: Salivary pH changes with paneer } & & \\
\hline Time interval & Mean & Std dev & Mean difference & $t$ & $p$-value \\
\hline Baseline pH & 6.92 & 0.28 & 0.178 & 2.637 & $0.017^{\star}$ \\
pH after eating chocolate & 6.74 & 0.24 & -0.628 & -5.636 & $<0.001^{*}$ \\
Baseline pH & 6.92 & 0.28 & & \\
pH after eating paneer & 7.54 & 0.37 & -0.806 & -9.657 & $<0.001^{*}$ \\
pH after eating chocolate & 6.74 & 0.24 & & \\
pH after eating paneer & 7.54 & 0.37 & & & \\
\hline
\end{tabular}

*Significant difference 


\begin{tabular}{|c|c|c|c|c|c|}
\hline Time interval & Mean & Std dev & Mean difference & $t$ & $p$-value \\
\hline Baseline $\mathrm{pH}$ & 6.93 & 0.27 & 0.144 & 1.292 & 0.214 \\
\hline $\mathrm{pH}$ after eating chocolate & 6.79 & 0.44 & & & \\
\hline Baseline $\mathrm{pH}$ & 6.93 & 0.27 & -0.367 & -2.807 & $0.012^{*}$ \\
\hline $\mathrm{pH}$ after eating cheese & 7.30 & 0.52 & & & \\
\hline $\mathrm{pH}$ after eating chocolate & 6.79 & 0.44 & -0.511 & -4.254 & $0.001^{*}$ \\
\hline $\mathrm{pH}$ after eating cheese & 7.30 & 0.52 & & & \\
\hline
\end{tabular}

*Significant difference

\begin{tabular}{lccccc} 
& \multicolumn{5}{c}{ Table 3: Comparison of salivary $\mathrm{pH}$ values recorded in the cheese and paneer groups } \\
\hline Group & Mean & Std dev & Mean difference & $t$ & $p$-value \\
\hline Paneer & 7.54 & 0.37 & 0.244 & 1.620 & 0.115 \\
Cheese & 7.30 & 0.52 & & & \\
\hline
\end{tabular}

after 5 minutes and gradually returning to resting values after approximately 60 minutes. When paneer and cheese were chewed following chocolate a maximum rise in $\mathrm{pH}$ was observed but the difference was not statistically significant $(\mathrm{p}>0.05)$ (Table 3$)$. Thereafter the $\mathrm{pH}$ gradually fell at 5 minutes but was much higher than resting values and remained high for approximately 15 minutes following which the $\mathrm{pH}$ reduced but had not returned to baseline values at 60 minutes (Graph 1).

\section{DISCUSSION}

One approach to estimate the acidogenic potential of food involves evaluation of the magnitude of the $\mathrm{pH}$ response following ingestion of food. Consequently, methods to measure oral $\mathrm{pH}$ include plaque sampling, touch electrodes and built in electrodes. ${ }^{13}$ A patient-specific approach using $\mathrm{pH}$ strips to assess the acidogenic potential of paneer and cheese was used in the present study which also aids in patient and parent diet counseling. Although salivary $\mathrm{pH}$ is not the only parameter that predisposes to dental caries it is an effective educational tool at the chairside and in school health education programs to educate smaller and larger groups on the nutritional and protective aspects of food as part of diet counseling.

Salivary $\mathrm{pH}$ is influenced by flow rate, duration of stimulation and calcium concentration, therefore, the subjects were instructed to chew all test foods for a minute to standardize the experimental conditions. Hence, we chose to record the salivary $\mathrm{pH}$ values after 5 minutes had elapsed since a minimum drop in $\mathrm{pH}$ after the chocolate challenge was seen at 5 minutes.

Prior to consumption of test foods resting salivary $\mathrm{pH}$ was recorded to provide baseline values against which the rise and drop in $\mathrm{pH}$ could be evaluated. The baseline values thus, measured were in the range of 6.4 to 7.4 and are similar to earlier reports. ${ }^{14}$ The results tend to confirm previous reports of salivary testing showing a subject-to-subject variation in response to test foods as individuals in a population differ considerably in salivary $\mathrm{pH}$ due to variation in caries susceptibility.

In the present study, a shallow drop in $\mathrm{pH}$ (acidic) was seen in $70 \%$ of subjects and is consistent with Stephan's

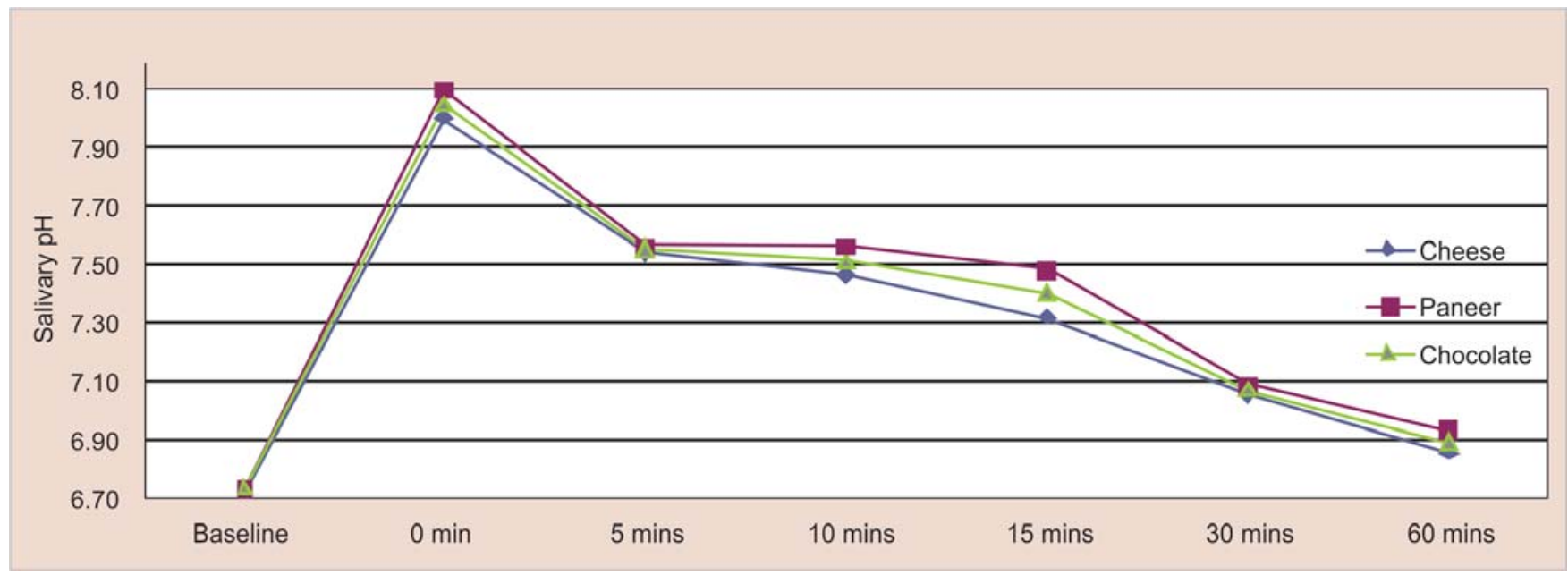

Graph 1: Change in mean salivary $\mathrm{pH}$ at different time intervals for all test foods 
observations that sugar containing foods cause a rapid drop in plaque (oral) $\mathrm{pH}^{15}$ This shallow $\mathrm{pH}$ response to chocolate maybe attributed to the difference in the method of assessing oral $\mathrm{pH}$ since, most studies assessed plaque $\mathrm{pH}$. However, in $30 \%$ of children no change in $\mathrm{pH}$ was detected. The probable reason for this lack in change in salivary $\mathrm{pH}$ maybe because their resting salivary $\mathrm{pH}$ was higher than 7.0 thus, had better buffering capacity and was similar to Birkhed's findings. ${ }^{14}$ Also the gustatory stimulus provided by eating chocolate further elevates salivary buffering capacity preventing the drop in $\mathrm{pH}$ and explains the rise in salivary $\mathrm{pH}$ seen in the first minute. High-sugar foods (chocolate, caramels) have a higher oral clearance as compared to high starch foods which maybe another contributing factor for the lack in change in salivary $\mathrm{pH} .{ }^{16,17}$ In addition since the subjects had good oral hygiene with minimal plaque it may have contributed to the lack in change seen in salivary $\mathrm{pH}$. It should be borne in mind that although the critical $\mathrm{pH}$ of 5.5 was not detected with $\mathrm{pH}$ strips after eating chocolate, it should not be considered as a safe food for teeth.

The rise in salivary $\mathrm{pH}$ due to cheese after chocolate challenge was similar to the results of Athena Papas; RuggGunn et al demonstrated a pH reversal when cheese was eaten after an exposure to sugar. ${ }^{2,18}$ In the present study a rise in salivary $\mathrm{pH}$ was seen in $82 \%$ of the subjects chewing paneer after a chocolate challenge. Harper et al have classified cheese into categories, such as fresh cream, soft, hard, etc. that reflect the differences in texture, aging, level of butterfat, casein and $\mathrm{Ca} / \mathrm{PO}_{4}$ content. ${ }^{19}$ Evidence suggests that hard cheese demonstrated alkaline $\mathrm{pH}$ values as compared to soft cheese and was in contrast to our finding. ${ }^{7,19-21}$ Furthermore, Pickerill stated that the nature of stimulus affects composition of saliva and an acid stimulus elicited secretion of saliva of high buffering capacity with sweet being the least. ${ }^{2}$ This was in contrast to our findings as paneer being a bland, semi-firm and unripened form of cheese produced minimal gustatory and mechanical stimulus as compared to processed cheese. Although both processed cheese and paneer caused an alkaline $\mathrm{pH}$ we found that paneer aided in faster neutralization of acidic saliva and this beneficial effect lasted for a longer time although not significant. In contrast, Krobicka et al demonstrated the protective effect of cheese was still present in desalivated rats indicating the possibility of other mechanisms. ${ }^{22}$ Casein phosphopeptides released by the proteolysis of cheese following intake lead to the formation of casein phosphopeptide-calcium phosphate complexes (CPP-CP) which increase calcium and phosphate in plaque thereby increasing its $\mathrm{pH}^{23,24}$ This maybe cited as the probable reason for recording higher $\mathrm{pH}$ values with paneer as it had a higher protein and $\mathrm{Ca} / \mathrm{PO}_{4}$ content as compared to processed cheese. Cheese may also protect against caries by reducing the adherence of mutans streptococci to tooth surfaces. ${ }^{25}$ Lipids in cheese may be protective by forming a coating on enamel surfaces which can reduce demineralization of tooth enamel surfaces and/ or by an antibacterial action of fatty acids. ${ }^{19}$ We can extrapolate these findings to explain the alkaline $\mathrm{pH}$ caused by intake of paneer. ${ }^{21}$

The substrate that causes a prolonged acidic $\mathrm{pH}$ is more detrimental to the teeth than its sugar content alone. ${ }^{2}$ In this study it was found that the fall in salivary $\mathrm{pH}$ caused by consuming chocolate reaching a maximum at 5 minutes and it took 60 minutes to revert to baseline values indicating the prolonged deleterious effect of chocolate consumption. The fall in salivary $\mathrm{pH}$ was rapidly reversed when followed by eating paneer and cheese and this protective effect reached a maximum at 30 minutes. However, even after an hour the salivary $\mathrm{pH}$ was higher than baseline values suggesting the prolonged caries protective effect of paneer and cheese.

Although the caries protective effect of cheese has been well-documented in the Western world, for the Indian subcontinent, indigenous products like paneer are more practical choices as they form a part of our traditional diet. The findings of this pilot study assessed indirectly the anticariogenicity of paneer thereby it maybe suggested as a final food in a meal as a caries protective measure.

Currently, most dental practitioners focus on merely providing dietary information which may be insufficient to bring about the desired change in behavior that can impact the success of nutritional counseling. ${ }^{26,27}$ Identification of effective educational methods to help the public translate dietary recommendations into appropriate food choices is the need of the hour. Therefore, our study proposes an out of the box thinking methodology of pediatric dietary counseling with the use of $\mathrm{pH}$ strips as a visual educational tool to encourage acceptance by giving out positive messages of following a sugary snack with a $\mathrm{pH}$ reversing food like paneer. This method gives the patient a sense of being in control of his diet as he can choose foods based on pH strip values, it is easy to do and can even be done as a fun activity by children thereby arousing their interest and hence may encourage better compliance. Additionally, it can be promoted as an educational campaign in school health programs and for children in practice by formulating quotes like 'Chew your way to pearly whites with paneer' or 'Chew your way to oral health naturally... chew paneer'.

\section{CONCLUSION}

In this study paneer like processed cheese reversed the drop in salivary $\mathrm{pH}$ levels after a chocolate challenge and the salivary $\mathrm{pH}$ levels were elevated for 60 minutes indicating 
that the protective effect of paneer lasted for over an hour. Hence, paneer can be recommended as a final food in a meal as a caries protective measure. Since, paneer is homemade and is a part of Indian diet it is a more economical choice than cheese for the Indian subcontinent. Hence, the findings of this study have demonstrated the method of creating a favorable environment to individual choice of healthier diets.

\section{Recommendations to Parents}

Allow children to choose foods by conducting the $\mathrm{pH}$ strip test. Dietary choices are largely governed by taste and it is impractical to suggest a sugar-free diet to a young child. Instead all healthcare providers should take cognizance of this new trend of chewing paneer or cheese after a sugary snack.

\section{To Dental Health Professionals}

To routinely use $\mathrm{pH}$ strips during diet counseling, so that didactic information is supplanted with a patient-specific visual tool. This method enhances patient's comprehension of the effect of his food choices on his teeth and how to negate its deleterious effects with protective foods.

\section{REFERENCES}

1. Manning RH, Edgar WM. pH changes in plaque after eating snacks and meals, and their modification by chewing sugared or sugar-free gum. Br Dent J 1993;174(7):241-244.

2. Edgar WM. Saliva and dental health. Clinical implications of saliva: report of a consensus meeting. Br Dent J 1990;169(3-4):96-98.

3. Rugg-Gunn AJ, Hackett AF, Appleton DR, Jenkins GN, Eastoe JE. Relationship between dietary habits and caries increment assessed over two years in 405 English adolescents school children. Arch Oral Biol 1984;29(12):983-992.

4. Geddes DAM, Edgar WM, Jenkins GN, Rugg-Gunn AJ. Apples, salted peanuts and plaque $\mathrm{pH}$. Br Dent J 1977;140:317-19.

5. Jensen ME, Harlander SK, Schachtele CF. Evaluation of the acidogenic and antacid properties of cheeses by telemetric monitoring of human dental plaque pH. In: Hefferren JJ, Osborn JC, Koehler HM(Eds). Foods, nutrition and dental health. Chicago, IL: American Dental Association 1984;4:31-47.

6. Koparal E, Ertugrul F, Sabah E. Effect of chewing gum on plaque acidogenicity. J Clin Pediatr 2000;24(2):129-132.

7. Leone CW, Oppenheim FG. Physical and chemical aspects of saliva as indicators of risk for dental caries in humans. J Dent Educ 2001;65(10):1054-1062.

8. Basics of paneer making/ what is the nutritional value of paneer http// www.cip.ukcentre.com/cheese.htm 5/10/10

9. Navazesh M. Methods for collecting saliva. Ann NY Acad Sci 1993;694:72-77.

10. Coulter C, Walsh LJ. Saliva testing: Good practice, good sense. Stepwise 2006;32-35.

11. Moynihan PJ, Ferrier S, Jenkins GN. The cariostatic potential of cooked cheese: Cooked cheese-containing meals increase plaque calcium concentration. Br Dent J 1999;187(12):664-667.

12. Sonmez IS, Aras S. Effect of white cheese and sugarless yogurt on dental plaque acidogenicity. Caries Res 2007;41(3):208-211.
13. Birkhed D. Sugar content, acidity and effect on plaque $\mathrm{pH}$ of fruit juices, fruit drinks, carbonated beverages and sports drinks. Caries Res 1984;18(2):120-127.

14. Bhalla S, Tandon S, Satyamoorthy K. Salivary proteins and early childhood caries: A gel electrophoretic analysis. Contemp Clin Dent 2010;1(1):17-22.

15. Ole Fejerskov, Edwina AM Kidd. Dental caries: The disease and its clinical management. 1st ed. USA: Wiley-Blackwell; 2003. $640 \mathrm{p}$.

16. Bibby BG, Mundorff SA. Enamel demineralization by snack foods. J Dent Res 1975;54(3):461-470.

17. Woodward $M$, Walker AR. Sugar consumption and dental caries: evidence from 90 countries. Br Dent J 1994;176(8):297-302.

18. Papas AS, Joshi A, Belanger AJ, Kent RL Jr, Palmer CA, DePaola PF. Dietary models for root caries. Am J Clin Nutr 1995;61(2):417S-422S.

19. Harper DS, Osborn JC, Hefferen JJ, Clayton R. Cariostatic evaluation of cheeses with diverse physical and compositional characteristics. Caries Res 1986;20(2):123-130.

20. Gedalia I, Ben-mosheh S, Biton J, Kogan D. Dental caries protection with hard cheese consumption. Am J Dent 1994; 7: 331332.

21. Peter J Huth. The role of cheese in healthful diets. Dairy Council Digest 2009;80(6):31-36.

22. Krobicka A, Bowen WH, Pearson S, Young DA. The effects of cheese snacks on caries in desalivated rats. J Dent Res 1987;66(6):1116-1119.

23. Azarpazhooh A, Limeback H. Clinical efficacy of casein derivatives. J Am Dent Assoc 2008;139(7):915-924.

24. Reynolds EC, del Rio A. Effect of casein and whey protein solutions on caries experience and feeding patterns of the rat. Arch Oral Biol 1984;29(11):927-933.

25. Rosen S, Min DB, Harper DS, Harper WJ, Beck EX, Beck FM. Effect of cheese, with and without sucrose on dental caries and recovery of Streptococcus mutans in rats. J Dent Res 1984;63(6):894-896.

26. Imfeld TN. Identification of low caries risk dietary components. H Myers, Basel S Karger (Eds). In: Monographs in Oral Science vol. 11.

27. Douglass JM. Response to Tinanoff and Palmer: Dietary determinants of dental caries and dietary recommendations for preschool children. J Pub Health Dent 2000;60(3):207-209.

\section{ABOUT THE AUTHORS}

\section{Tabassum Tayab (Corresponding Author)}

Senior Lecturer, Department of Pedodontics, MR Ambedkar Dental College and Hospital, Bengaluru, Karnataka, India e-mail: drtabassum2001@yahoo.co.in

\section{Kavitha Rai}

Professor, Department of Pedodontics, AB Shetty Dental College Mangalore, Karnataka, India

\section{Vasantha Kumari}

Professor and Head, Department of Pedodontics, Sri Ramachandra Dental College and Hospital, Chennai, Tamil Nadu, India

\section{Eapen Thomas}

Assistant Professor, Meenakshi Ammal Dental College, Chennai Tamil Nadu, India 